\title{
Analysis of Network Consumption Based on Economic law
}

\author{
Bangyu Wang* \\ Sichuan University Law School, Chengdu, Sichuan 610065, China \\ *Corresponding author. Email: 330115925@qq.com
}

\begin{abstract}
The rise of the Internet has promoted the rapid development of online consumption, but at the same time various online consumption disputes have become increasingly acute, and the legislation for the protection of the rights of Internet consumers, such as security, privacy and information, is imperfect or lack of operability. From the perspective of the value of economic law, this paper analyzes the protection of the rights and interests of Internet consumers from a higher level by expounding the value of economic law such as social standard, fairness and safety.
\end{abstract}

Keywords: Network consumption, value, economic law

\section{INTRODUCTION}

In 1969, the United States first created the Internet, after decades of rapid development, now has become an indispensable part of people's lives. The popularization of the Internet has directly promoted the development of electronic commerce [1].

In 2013, alibaba's "eleven" day turnover of 35 billion yuan. A year later, on November 12,2014, Alibaba announced that "eleven" day turnover exceeded 50 billion yuan [2]. The existence and popularization of network brings great convenience to people's real life. According to the 29th Statistical Report on China's Internet development, released by the China Internet Network Information Center in Beijing on January 16,2012, China's internet population surpassed 500 million at the end of December 2011, reaching 513 million, 55.8 million new Internet users. Internet penetration is up 4 percentage points from the end of last year to $38.3 \%$ [3], and by 2016, the world's Internet is expected to have 3 billion users.

According to the data of the 35th China Internet development statistics report in 2015 [4], the number of internet shoppers reached 361 million by December 2014, an increase of 59.53 million from the end of 2013, an increase of 19.7 percent. The proportion of Chinese netizens using the Internet to buy goods has increased from $48.9 \%$ to $55.7 \%$ [5], the legislation on the protection of the rights of Internet consumers, such as the right to security, the right to privacy and the right to know, is imperfect or lack of operability, fairness and security.

\section{The Value of Economic Law and the Value of Protecting the Rights and Interests of Internet Consumers}

The emergence of economic law broke through the boundary of the dualistic division between public law and private law of Ulbian, an ancient Roman scholar, and formed a "third jurisdiction" between public law and private law, the principle of party autonomy is also emphasized. It is different from the national standard of public law and the individual standard of private law in value and idea, but takes the social standard as the foundation of legislation and law enforcement. The protection of the rights and interests of Internet consumers is mostly inclined to the category of economic law. Therefore, the analysis and orientation of the value of economic law is more helpful to solve various problems in the process of Internet consumption.

\subsection{The definition of the value orientation of economic law}

Value is not an exclusive term of law, it can be applied in different fields. It is also understood differently in different domains. From the perspective of jurisprudence, it can be simply understood as the "usefulness" of the law of the object to the person of the subject. It has the functions of guidance, evaluation, prediction, compulsion and education. Such as the law symbolizes order, fairness, justice; the law can guarantee people's personal security, property security; the law can guide people what can be done, what cannot be done... The emergence of economic law in the West went through the process from mercantilism to liberal capitalism to monopoly capitalism, through the evolution from Adam Smith's invisible hand to Keynes's invisible hand. Therefore, the economic law has been doomed to the social standard since its birth, and its value orientation is different from the fairness and freedom of the traditional civil and commercial law and the moderate intervention of the state. 


\subsubsection{The social interest standard value of economic law}

The economic law is that the market mechanism cannot effectively adjust the economy, however, due to the existence of insufficient or lost information, excessive decision-making cost, lack of wisdom of decision-makers, and the restriction of interest of decision-makers (the theory of government failure)1, the government regulation may be out of order when it is in its own way, the emergence of Economic Law. Therefore, the economic law from the birth of both the shadow of private law, but also the existence of appropriate state intervention that is public law. The interests he protects are not the simple addition of individual interests in traditional private law, such as civil and commercial law, nor are they exactly the same as the national interests, but the promotion of individual interests and national interests through the realization of the overall interests of society. This requires the state to maintain and realize the overall interests of the society as the goal when carrying out Macroeconomic regulation and control and market regulation, likewise, we should not only pursue our own interests but ignore the interests of the whole society. With the increasing popularity of network consumption, the protection of network consumers is no longer a problem of individual consumers, it involves the whole consumer social groups, the stability of e-commerce operation and the economic order of social order. Therefore, it has higher theoretical value and practical significance to study the protection of Internet consumers' rights and interests from the social interest standard value of economic law.

\subsubsection{The value of substantive justice through law}

In Ancient Rome, the goddess of Justice with a balance in her left hand and a sword in her right represented justice and fairness. The fundamental aim of law is to realize fairness. The historicity of law and equity determines that there are different types of justice in different historical periods, different legal systems, different countries and political and economic systems. The justice pursued by the private law represented by the traditional civil and commercial law is a kind of justice in form and in starting point. Whether you were born with a silver spoon in your mouth, or you were born poor with nothing, or whatever your natural endowments... Civil and commercial law places everyone on the same starting line and gives everyone the same rights, this starting point of fairness in the market economy can not necessarily lead to the outcome of fairness. The fairness pursued by economic law is more inclined to result fairness and substantial fairness, that is to say, both formal fairness and substantial fairness. In the process of network consumption, consumers and business operators belong to the main body of the market and the parties to the contract of sale and purchase (service), but economic law does not put them on the same starting line and give them the same rights as traditional civil and commercial law. Because in this fictitious trade process, although be the main body of the market together, but the network consumer is in the position of weak person apparently. Therefore, should endow the network consumer with more rights, but opposite party operator should undertake more obligations. Through this imbalance of rights and obligations in law, to achieve the protection of the weak, as far as possible to achieve the results of fair, substantive fairness.

\subsection{The value of protecting the rights and interests of Internet consumers}

The popularization of Internet has promoted the rapid development of e-commerce. The time and space that restrict traditional marketing are no longer important in the network era. Whether B2b business-to-business marketing relationship, B2C BUSINESS-TO-CUSTOMER OR C2C individual-to-individual e-commerce model, transactions are conducted in a virtual environment, there is a lack of traditional face-to-face transactions in the hand-to-hand money, a down payment of intuitive. The network consumer is in the weak position in the whole transaction process, lacks the necessary understanding to the transaction commodity (service), you can only judge a product (service) by the pictures, words, and reviews of other traders posted on the Internet. At the same time, consumers usually have to provide some information of their own, personal privacy protection depends entirely on the business ethics. These problems directly affect the fairness and security of the whole network transaction, as well as the economic order of the society. Both ordinary consumers and Internet consumers, they are the main body of the entire market economy, once they lose confidence in the market, it also represents the decline of the overall purchasing power of society, it will certainly have an impact on social and economic development. Therefore, through the regulation of network consumption, it is of great research value to stop the Unfair competition, protect the legal rights and interests of network consumers, stabilize the growth target, maintain the healthy operation and harmonious development of the economy and society.

\section{The Current Situation of the Protection of Internet Consumers Rights and Interests in China}

\subsection{The problems of network consumption}

The biggest difference between the network transaction and the traditional transaction is that it is accomplished under the virtual form. In the transaction process, consumers can not like the traditional transaction of goods (services) can touch, try, there is no sight for the advantages of traditional transactions. All consumers know 
about the goods (services) can only rely on the online description of the goods (services) language, upload the relevant pictures, as well as other consumers online shopping evaluation. All this virtual content makes it easier to fake and cheat. For example, when consumers consider buying a product (or service), they often use online reviews of the product (service) by other consumers as an important reference.

As a result, the satisfaction of the online review, "satisfaction", "dissatisfaction", "excellent review", "poor review" has become an indispensable bargaining chip in business marketing, which has also given birth to the "professional modification of poor review" industry. At the beginning of the New Year in 2015, five people, including those prosecuted by the Binjiang district procuratorate in Hangzhou City, Zhejiang province, contacted Taobao sellers who needed to revise "Zhongping" and "poor pingping" to charge 260 yuan for a single evaluation, it made more than 90,000 yuan in 2011 and 2012. Although they were eventually sanctioned by the law, it also made consumers see that the online reviews they relied on did not reflect the true quality of the goods (services), or even the true intentions of other consumers.

Because online transactions are conducted in an open network and a virtual trading environment, online consumers generally do not see the transaction of the relative person, once the phenomenon of merchants infringing the interests of online consumers, they usually walk away, change an identity to register afresh, bring difficulty to superintendency branch, more bring difficulty to defend the right of consumer of net shopping. The low cost and convenience of online shopping will certainly replace the traditional shopping model to some extent. Virtual enterprises, virtual banks, network marketing and so on will make the future development of ECOMMERCE era. Therefore, how to effectively protect the right to know, personal and property safety, privacy, Square Deal, and how to create an efficient, fair and orderly online trading environment is of paramount importance, this is also the embodiment of the external or subjective value of economic law.

\subsection{The current situation of network consumption legislation in China}

With the popularization of Internet and the rapid development of E-commerce, China's legislation on the Internet has accelerated in recent years. The Electronic Signature Law of the People's Republic of China, which came into force on 1 April 2005, has drawn on the advanced experience of the United Nations Model Law on electronic commerce and the relevant legislation of the United States, the European Union and other countries, in our country electronic commerce development history has the vital significance. One of the highlights of the law of the People's Republic of China on the protection of consumers'rights and interests, which was amended in 2013 and implemented on March 15,2014, is that it has made more explicit provisions on some hot issues concerning the protection of consumers'rights and interests. Such as giving online consumers a 7-day "cooling-off period" (article 24), regulating the online consumers "no reason" return system (article 25), giving the consumer association new functions, so that the collective protection of online consumers have a certain protection (Article 37) ; Article 44 provides for the liability of the Internet platform to pay in advance for goods purchased on the Internet Platform; the penalties for consumer fraud have been increased from twice to three times (article 55) ... At the same time, a number of Local ordinance, departmental regulations have also made provisions for online consumer protection. Such as February 1,2003, the implementation of the Guangdong electronic transactions regulations, 2014 issued by the State Administration for Industry and Commerce, the network transaction management measures.

Although the legislative process has been advancing continuously in recent years, due to the late development of the popularization and application of the Internet and ecommerce technology in China, relative to the relevant legislation on the Internet in developed countries such as the United States and Europe, China is still in a backward state, lack of a perfect system, some laws and regulations are too broad, lack of applicability, the protection of consumer rights and interests of the network transactions legislation and the rapid development of the network transactions economy is in a backward situation.

\section{On the Protection of Internet Consumers Rights and Interests from the Perspective of Safety Value}

The role of law is to maintain social order, to protect the subject's personal safety and property security from infringement. No matter economic law or other department law, the safety value should be the goal that the legislator pursues. The security value pursued by economic law is based on its social standard value, which indirectly realizes the protection of individual interests through the protection of the interests of the majority and the whole of the society rather than the individual. The virtual nature of network transaction and the open nature of the network directly lead to the quality of goods purchased online, the protection of consumers' personal privacy, online payment problems and the difficulty of safeguarding their rights.

The value of safety requires that the consumers who are in the weak position should be given adequate security in the transaction. From the perspective of the Social Standard of economic law, the safety of online shopping represents the stability of the overall economic order of the society, and is the primary consideration of the government in regulating the economic Macroeconomic regulation and control and the market. Not only to intervene, but also can not violate the law of economic development, the moderation of intervention needs the government to deal with rationally. In addition, online consumers should also 
strengthen their ability to identify and resist risks, strengthen the concept of the legal system and the meaning of safeguarding rights, so that illegal operators have no opportunity.

\section{On the protection of Internet Consumers Rights and Interests from the Perspective of Fair Value}

Today's goods and services operators, is no longer a mere small handyman, they have strong funds, advanced production technology, a wide range of information sources channels. But as the individual individual individual individual net buys the consumer to be impossible to have with its "the confrontation" the strength. If, as in the traditional civil and commercial law, the two parties to a transaction contract place the online consumer and the business operator on the same starting line, endow them with the same rights and obligations, this would be contrary to the economic law of the pursuit of substantive fairness, the results of fairness. Even online shopping operators occasionally exist in the form of an individual, but because of the virtual nature of online shopping, online shopping consumers cannot be like traditional transactions on goods (services) touch, try. The characteristics of online shopping doomed to online shopping consumers of goods (services) can only be derived from the description of the language on the network and uploaded pictures, the authenticity of all this depends more on the honesty of business ethics and strong government supervision.

In addition, in addition to the above-mentioned network transactions between the two parties, capital, strength, Information asymmetry and other factors, format contract is also an obstacle to the Square Deal. The format contract is usually adopted in online shopping, online shopping consumers have no more choice, for the format of the contract in some of the "overlord clause", or recognition, or give up the transaction. Therefore, the protection of the weak online consumers should not follow the traditional fair view, the rights should be more inclined to the weak, operators should assume more obligations. Substantive fairness and result fairness will break through the complete correspondence of traditional rights and obligations.

\section{On the Protection of Internet Consumers Rights and Interests from the Perspective of the Value of Honesty and Credit}

Although the rights and interests of Internet consumers have been damaged due to the lack of mutual funds, strength, Information asymmetry and government supervision, the root cause of the problem is the loss of traditional moral concepts, is the loss of the principle of honesty. In the network shopping, the false propaganda, returns the goods difficultly, maintains the authority difficultly, the personal information divulges and so on the final test is the merchant's good faith. The lack of honesty and credit has pushed forward the flood of "egoism" such as making, selling and cheating in the market economy. "The Fugitive, not leak" is only an ideal state of society. The law has certain stability, once promulgates the implementation, may not revise consummates without the legal procedure. Laws cannot cover new situations and problems that occur every day, and government regulation is also limited by time, space, manpower and material resources. Therefore, in the process of economic exchanges, the more decisive factor or the conscience of both sides of the transaction, has been hidden in the heart of the moral standards.

E-COMMERCE has promoted the development of online transactions. Despite the advantages of low cost and convenience, there are many problems such as the difficulty in protecting the rights and interests of online consumers. We should strengthen the protection of the rights and interests of online shopping through improving laws and regulations, strengthening self-discipline of industry, improving the meaning of self-protection, and the synergy of soft law and hard law.

\section{REFERENCES}

[1] Can More Nanoparticles Induce Larger Viscosities of Nanoparticle-Enhanced Wormlike Micellar System (NEWMS)?[J]. Zhao Mingwei, Zhang Yue, Zou Chenwei, Dai Caili, Gao Mingwei, Li Yuyang, Lv Wenjiao, Jiang Jianfeng, Wu Yining. Materials (Basel, Switzerland). 2017(9)

[2] Chemical composition and antioxidant capacity of extracts from the whole berry, pulp and seed of Hippophae ${ }^{.}$rhamnoides ssp. yunnanensis.[J]. Shi Longkai, Zheng Li,Zhao Chenwei, Jin Qingzhe, Wang Xingguo. Natural product research. 2019(24)

[3] Hedgehog signaling pathway regulates liver regeneration in the Fah-/- knockout mice model xenografted by human hepatocytes.[J]. Xu Xiaoqing, Jiao Xiaohu, Jiao Yuhong, Wang Min, Jiao Chenwei. International journal of clinical and experimental pathology. 2017(9)

[4] Investigation of Novel Triple-Responsive Wormlike Micelles.[J]. Zhao Mingwei,Gao Mingwei,Dai Caili,Zou Chenwei,Yang Zhe, $\mathrm{Wu}$ Xuepeng,Liu Yifei,Wu Yining,Fang Sisi,Lv Wenjiao. Langmuir : the ACS journal of surfaces and colloids. 2017(17)

[5] Mining human cancer datasets for kallikrein expression in cancer: the ' KLK-CANMAP' Shiny web tool.[J]. Wang Chenwei,Moya Leire,Clements Judith A,Nelson Colleen C,Batra Jyotsna. Biological chemistry. 2018(9) 